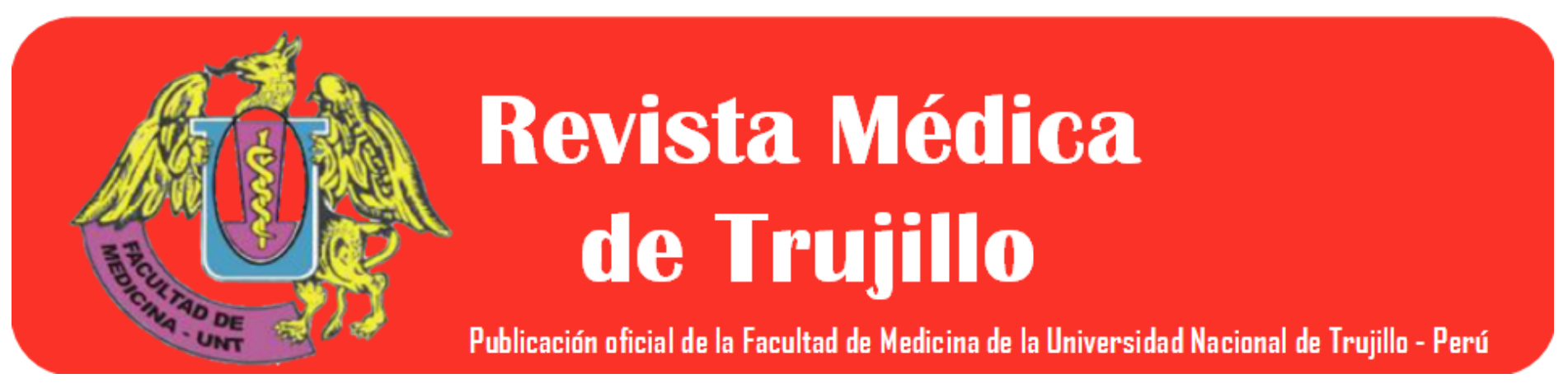

Editorial

\title{
Vacunas contra el COVID-19
}

\section{Vaccines against COVID-19}

La pandemia del COVID-19 en la fecha de esta publicación ha alcanzado un total de 62147874 infectados y 1450326 fallecidos. Estados ocupa el primer lugar seguido de India, Brasil, Francia y Rusia. Perú presenta ocupa el lugar 14 con 958324 de infectados y 35839 fallecidos $^{1}$. Comparado con el 9 de agosto del número anterior, en 3 meses 19 días el total de infectados se ha triplicado en el mundo y el número de muertes se ha duplicado, en el Perú el número de infectados se duplicó y el de fallecidos se multiplicó por 1.7 Aún no se cuenta con un tratamiento específico .

La rápida identificación de la estructura viral, la identificación de la proteína espiga que se une a los receptores de la enzima convertidora de la angiotensina, ha permitido acelerar el desarrollo de las vacunas ${ }^{2}$. La OMS indica que se están desarrollando más de 169 vacunas candidatas contra la COVID-19, de las cuales 36 se encuentran en fase de ensayos en humanos ${ }^{3}$. Varias características se señalan para una vacuna ideal ${ }^{4}$ : seguridad con pocos efectos secundarios, conferir protección por periodos prolongado en más del 80 $\%$ de la población especialmente en adultos mayores y población susceptible como con obesidad, una simple dosis, gran producción en poco tiempo, facilidad de almacenamiento $y$ transporte, que sin embargo no siempre se cumplen, pero lo prioritario sería su seguridad y acción protectora rápida para estadios moderados $\mathrm{y}$ severos, y los más susceptibles ${ }^{4}$. Los estudios de eficacia implica el control de las variables en los voluntarios como la edad, factores de riesgo, niveles de protección o de exposición, sus-ceptibilidad personal entre otros.

Hay que señalar que por su naturaleza las vacunas pueden ser a base de virus inactivado, proteínas virales como la de la espiga que requieren adjuvantes en los adultos mayores, DNA con vectores virales, vacunas genéticas con RNA viral ${ }^{5,6}$ 7,8. Las vacunas con RNA requieren una conservación más exigente que puede llegar a $-70^{\circ} \mathrm{C}$, pero se están buscando alternativas para su mejora, como una capa lipídica.

Se espera que en los primeros meses del 2021 se pueda contar con una vacuna que detenga esta expansión que afecta tanto la salud física y mental, la economía, la educación y todos los campos a nivel mundial. La educación médica en particular la de pregrado se ha visto afectada por la pandemia, solo se realiza la enseñanza no presencial, y la presencialidad que es tan importante y esencial en la formación médica tiene que esperar la llegada de las vacunas para no exponer a los estudiantes.

Los países se están preparando, el Perú entre ellos, organizando una programación de aplicación. El inicio sería con los más expuestos como el personal de salud o militar y los más susceptibles como los

DOI: http://dx.doi.org/10.17268/rmt.2020.v15i04.01 
adultos mayores. Mientras tanto solo quedan las medidas preventivas conocidas como el uso de la mascarilla, lavado de manos y el distanciamiento social, y no disminuir su cumplimiento ante la eventual llegada de la vacuna

Juan Jorge Huamán-Saavedra

1. John Hopkins University. Coronavirus Research Center. Covid-19. 28 de noviembre 9.40 p.m 2020 (Citado 20 de noviembre 2020) Disponible en https://coronavirus.jhu.edu/map.html

2. Srinivasan S, Cui H, Gao Z, Liu M, Lu S, Mkandawire W, et all. Structural Genomics of SARS-CoV-2 Indicates Evolutionary Conserved Functional Regions of Viral Proteins. Viruses. 2020; 12(360).

3. World Health Organization [Internet]. Draft landscape of COVID-19 candidate vaccines; 2020 [citado el 29 de noviembre del 2020]. Disponible en: https://www.who.int/publications/m/item/draft-landscapeof-covid-19-candidate-vaccines.
4. Privor-Dumm L, Bar-Zeev N, and Moss W. . International Vaccine Access Center. Types of COVID-19 Vaccines (citado 29 de noviembre 2020) Disponible https://coronavirus.jhu.edu/vaccines/reports/types-ofcovid-19-vaccines

5. Preet S, Gupta V. COVID-19 Vaccine: A comprehensive status report. Virus Res 2020 Oct 15;288:198114. doi: 10.1016/j.virusres.2020.198114

6. Hodgson S, KushalMansattaB, Mallett G, Harris V, Wemary RBM, Pollard J. What defines an efficacious COVID-19 vaccine? A review of the challenges assessing the clinical efficacy of vaccines against SARSCoV-19 The Lancet Inf. 2020 (oct).

7. Locht C. Vaccines against COVID-19 Anaesthesia Critical Care \& Pain Medicine 2020 (Oct) (citado 29 noviembre 2020) Disponible en https://www.sciencedirect.com/science/article/pii/S23525 5682030237X?dgcid=rss_sd_all

8. Lanata De las Casas C, Gotuzzo Herencia E. Estrategias y situación actual de la carrera para el desarrollo de vacunas contra el Sars-COV-2. Editorial Rev Peru Med Exp Salud Publica. 2020;37(3):401-2 